not with mental health and those familiar with mental health but not with deaf people". They have succeeded in the second of these aims, but deaf or hearing people completely new to the mental health field would probably benefit from reading a mainstream introductory text in the first instance.

The contributors, experienced deaf and hearing professionals from Britain and the USA, describe the epidemiology and assessment of deafness, the deaf cultural community and the assessment and management of mental health problems in this population. This is a difficult task, as many complex factors operate. Deafness is technically a disability measured by doctors and audiologists. For those with acquired loss it is a deficit and all too often a social stigma. However, for those people who are profoundly deaf from early life the issues are different. Although about $90 \%$ of them are born into hearing families and many have little or no access to sign language in childhood, many grow up to identify themselves as members of the deaf community, with its pride in deaf culture and language. Unfortunately, the limitations in age-appropriate language development and in educational and social opportunities that so often occur during a deaf person's childhood may leave a legacy of frustration, underachievement, dependency and low self-esteem that can lead to mental health problems in adult life. Deaf children are also more likely to be victims of abuse, emotional, physical or sexual. They may have additional difficulties, such as sight, neurological or learning problems, possibly associated with the cause of the deafness (e.g. meningitis and rubella).

Psychiatric illnesses such as affective disorder and schizophrenia occur with equal frequency in deaf and hearing people. However, delays and difficulties in diagnosis and lack of access to appropriate services have too often meant that deaf people have not received proper help, or that they have remained in institutional settings, sometimes without adequate communication, for long periods. This book addresses all of these issues from different professional perspectives.

There are several recurring themes, such as the importance of appropriate knowledge, attitudes and communication skills in the assessment and treatment of deaf people and how all of these are greatly enhanced by the involvement of deaf people themselves in service provision: Peter Hindley's chapter shows how risk factors in the childhood of deaf people can be tackled. Other excellent chapters include those on psychological therapies, the role of interpreters and rehabilitation.

As society develops a more positive attitude to minority groups, it is to be hoped that there will be a raised awareness of deaf people's rights to services as outlined by the Disability Discrimination Act, the National Service Framework (Department of Health, 1999) and the Health Advisory Service (1998) report Forging New Channels. Mental Health and Deafness is to be commended as a valuable contribution to this process.

Department of Health (1999) The National Service Framework for Mental Health. Modern Standards and Service Models. London: Department of Health.

Health Advisory Service (1998) Mental Health Services: Forging New Channels. Beaconsfield: Sign.

Margaret du Feu Consultant Psychiatrist, Denmark House, Queen Elizabeth Psychiatric Hospital, Mindelsohn Way, Edgbaston, Birmingham BI5 2QZ

\section{Psychoanalysis on the Move: The Work of Joseph Sandler}

Edited by Peter Fonagy, Arnold M. Cooper \& Robert S.Wallerstein. London: Routledge. 1999. 237 pp. $€ \mid 8.99$ (pb). ISBN 0415205492

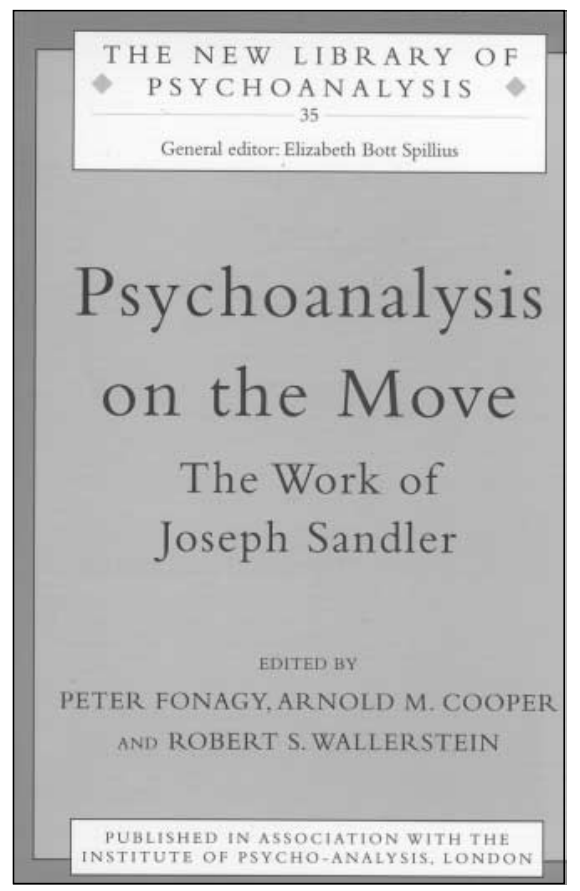

I did wonder why the publishers had not included this book in their excellent series, 'The Makers of Modern Psychotherapy', but I presume it is because Sandler was still alive (sadly, he died during the preparation of the book). In fact, it has been included (as no.35) in another series, 'The New Library of Psychoanalysis', the object of which is ". . . to provide a forum of increasing mutual understanding between psychoanalysts and those working in other disciplines" (p. ii). In this, I believe it has failed. It is written by psychoanalysts for psychoanalysts, and makes no concessions to the non-psychoanalytic reader. Few references are made to work outside of psychoanalysis (though Segal does draw parallels with Chomsky's view of language), and little interest is shown in establishing connections between psychoanalysis and other disciplines. Implicit in much of what is written is that psychoanalysis is so much a unique approach, that it would be seriously compromised if it made concessions to alternative approaches. I am sure this is not true.

The book assumes the form of a festschrift. Consequently, only in the first chapter do we get a (very necessary) overview of Joseph Sandler's major contributions. We are told that he helped to close the gap between the American ego psychologists and the British Kleinian and object relations theorists. The remaining 14 chapters comprise a series of essays by eminent psychoanalysts on issues that are linked to Sandler's preoccupations, but say very little about him. In their review of these essays, Fonagy \& Cooper use such phrases as breathtaking, masterfully brilliant, exceptionally lucid, wonderfully erudite and scholarly. I found them to be dense, convoluted and packed with undefined, psychoanalytic jargon. I consider psychoanalysis to be one of the few disciplines to take account of the true complexity of human thinking, but I also consider the task of the theorist to be to clarify and simplify.

We are told that Sandler aimed to divest psychoanalysis of conceptual confusion, that he was preoccupied with the multiple and frequently incompatible meanings attached to terms and concepts, and that his writing is a tribute to the tolerance of ambiguity required of theoreticians such as himself. That its practitioners attach different meanings to its terms and concepts is no great advertisement for psychoanalysis. Most of the contributors here are concerned with the definition of terms. Terms such as enactment, internal object, narcissistic cathexis, unconscious fantasies and the patient's representational world are 
certainly in need of clarification, and it was helpful to witness the contributors grappling with them.

The book's title is an overstatement: psychoanalysis is such a static discipline that when it moves it moves only slightly. The movement lies only in the detail. The basic ingredients remain in place. Interpretation is still the principal therapeutic strategy. All dreams are still considered to be wish fulfilments, even when they so obviously are not. The Oedipus complex remains a central concept: one contributor even considers it to be hard-wired. In short, psychoanalysis continues to turn in upon itself, which, in the long run, can only be to its detriment.

John Birtchnell Senior Lecturer, Institute of Psychiatry, de Crespigny Park, London SE5 8AF

\section{Drugs: Dilemmas and Choices}

By a Working Party of the Royal College of Psychiatrists and the Royal College of

Physicians. London: Gaskell. 2000. 304 pp. $£ 9.50$ (pb). ISBN I 901242447
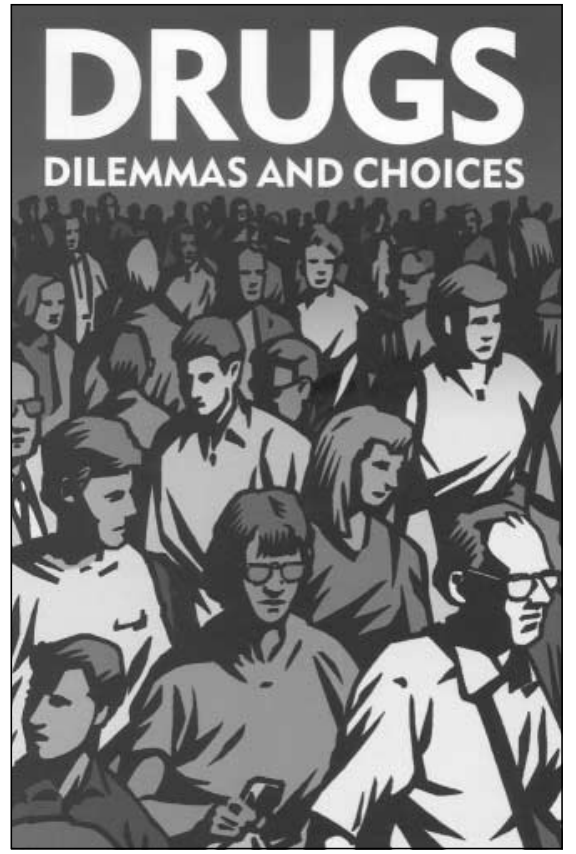

The production of a major review of international and national drug policy is a feat of juggling and balance. This report was published in the same week as the Police Foundation Report. The latter, which called for some minor changes in the drug laws, made the headlines of all the national daily newspapers, partially because the Government rapidly rejected its recommendations. By contrast, the former received a much quieter reception, probably because it chose not to make radical recommendations about changes in the law and in drug policy. You might infer, then, that this is a tame 'establishment' document. However, you should think again. Within its 300 pages of text are some thoughtprovoking and challenging questions about the nature of modern drug policy.

The report outlines how attitudes to drugs are based largely on the assumptions, prejudices, customs and economic interests of key nations. In particular, the major international conventions of the early 20th century were drafted with a dominant Anglo-Saxon influence. The voices of Asia, the Middle East and Latin America were barely heard.

Illicit drug use has increased steadily year on year for the past decade. Globally we have witnessed the diffusion of injected drug use from a small number of Western countries to over 130 nations, with an associated rapid spread of HIV and hepatitis C. International drug policy is caught up with dominant economic interests, changed by major wars and revolutions, and involved in the corruption of many governments. Drug trends are altered by new production and distribution technologies. Sport, which was once seen as a critical part of drugs prevention and which symbolised clean healthy living, has now become another area for drug misuse, with a range of new performance-enhancing drugs being developed.

Over two-thirds of resources expended on drug policy are spent on enforcement, including police, prisons, customs and international interdiction. This report highlights the paradox of such spending, pointing out that there is currently little evidence to support it. The Government annually spends $£ 1.4$ billion combating drugs. The report recommends that there should be a shift to ensure that about $50 \%$ of this is spent on primary and secondary prevention and treatment. It also calls for a substantial increase in the amount spent on research, noting that just $1 \%$ would inject $£ 14$ million per annum into drugs research.

Recent research from both the USA and the UK indicates that drug treatment is effective in reducing levels of drug consumption and, consequently, levels of drugrelated crime. The National Treatment Outcome Research Study reported a saving of $£ 3$ for every $£ 1$ spent on treatment
(Healey et al, 1998). The report strongly supports the further development of treatment for drug dependence and notes that there is a significant lack of treatment for amphetamine users and young people. The national plan of the current UK Anti-Drugs Coordinator (the 'Drug Tsar') stresses the need for a radical increase in the number of treatment places. It is now necessary to ensure that appropriate resources are made available to support such service expansion, which the report emphasises should be directly linked to the percentage of the population requiring treatment for drug problems.

There is a finely balanced discussion of policy options regarding cannabis, and the report states that social experiments such as that of the Dutch Government should be encouraged and fully researched. The authors also argue that it is difficult to justify imprisoning someone simply for personal possession or personal use of cannabis. The report appears tacitly to support the expansion of prescribing heroin as an alternative to methadone and implies that such a shift could result in the de facto legalisation of heroin, stating that such a policy would be readily reversible if illeffects started to mount.

The Working Party concludes that if drug consumption and its negative consequences continue to mount at the current rate, it is likely that there will be a shift from comprehensive prohibition to some form of legalisation. They call for policy to be developed through the objective appraisal of the consequences of previous policy changes rather than on the basis of moral postures, the mistaken assumptions of the past and accidents of history.

Repeatedly, the text argues for an approach in which reason and argument triumphs over passion and belief. It tries to keep all options open and provides an important framework that should make it essential reading for politicians and policymakers. The lack of specific recommendations reduces the punch of this report but my guess is that it will gain in reputation and impact over time.

Healey, A., Knapp, M., Astin, J., et al (1998) Economic burden of dependency. social costs incurred by drug users at intake to the National Treatment Outcome Research Study. British Journal of Psychiatry, 173, 160-165.

Michael Farrell Senior Lecturer and Consultant Psychiatrist, National Addiction Centre, Institute of Psychiatry, 4 Windsor Walk, London SE5 8AF 